\title{
Transcriptional silencing of a transgene by RNAi in the soma of C. elegans
}

\author{
Alla Grishok, ${ }^{1}$ Jina L. Sinskey, ${ }^{1}$ and Phillip A. Sharp ${ }^{1,2,3}$ \\ ${ }^{1}$ Center for Cancer Research, ${ }^{2}$ Department of Biology, ${ }^{3}$ McGovern Institute, Massachusetts Institute of Technology, \\ Cambridge, Massachusetts 02139, USA
}

\begin{abstract}
The silencing of transgene expression at the level of transcription in the soma of Caenorhabditis elegans through an RNAi-dependent pathway has not been previously characterized. Most gene silencing due to RNAi in C. elegans occurs at the post-transcriptional level. We observed transcriptional silencing when worms containing the elt-2::gfp/LacZ transgene were fed RNA produced from the commonly used L4440 vector. The transgene and the vector share plasmid backbone sequences. This transgene silencing depends on multiple RNAi pathway genes, including $d c r-1, r d e-1, r d e-4$, and $r r f-1$. Unlike post-transcriptional gene silencing in worms, elt-2::gfp/LacZ silencing is dependent on the PAZ-PIWI protein Alg-1 and on the HP1 homolog Hpl-2. The latter is a chromatin silencing factor, and expression of the transgene is inhibited at the level of intron-containing precursor mRNA. This inhibition is accompanied by a decrease in the acetylation of histones associated with the transgene. This transcriptional silencing in the soma can be distinguished from transgene silencing in the germline by its inability to be transmitted across generations and its dependence on the rde-1 gene. We therefore define this type of silencing as RNAi-induced Transcriptional Gene Silencing (RNAi-TGS). Additional chromatin-modifying components affecting RNAi-TGS were identified in a candidate RNAi screen.
\end{abstract}

[Keywords: RNAi; RNAi-TGS; RNAi-PTGS; dsRNA; siRNA; L4440]

Supplemental material is available at http://www.genesdev.org.

Received August 9, 2004; revised version accepted January 26, 2005.

In many organisms, gene silencing induced by homologous RNA plays an important role in protection against viruses and mobile genetic elements while also serving a regulatory function during development. The discoveries of RNA interference (RNAi) (Fire et al. 1998), short interfering RNAs (siRNAs) (Hamilton and Baulcombe 1999; Hammond et al. 2000; Zamore et al. 2000; Elbashir et al. 2001) and Dicer (Bernstein et al. 2001), the conserved RNase III-type protein required for production of siRNA from double-stranded RNA (dsRNA), brought together observations in different organisms to establish RNA-mediated silencing as an essential biological phenomenon. These discoveries also stimulated the recognition of a connection between siRNAs and microRNAs (for review, see Bartel 2004) in addition to implicating siRNAs and RNAi in chromatin silencing (Hall et al. 2002; Volpe et al. 2002).

The connection between RNAi and transcriptional silencing has been best studied in fission yeast, where siRNAs corresponding to centromere repeats have been found (Reinhart and Bartel 2002) and the RNAi pathway

${ }^{3}$ Corresponding author.

E-MAIL sharppa@mit.edu; FAX (617) 253-3867.

Article published online ahead of print. Article and publication date are at http://www.genesdev.org/cgi/doi/10.1101/gad.1247705. genes dicer, argonaute, and RNA-dependent RNA polymerase (RdRP) have been implicated in silencing at centromeres (Hall et al. 2002; Volpe et al. 2002). The hallmark of silenced chromatin is Histone 3 Lys 9 (H3-K9) methylation by the methyltransferase Clr-4 and association of H3-K9 with Swi6, a chromodomain protein homologous to Heterochromatin Protein 1 (HP1) (Hall et al. 2002; Volpe et al. 2002). The complex containing siRNAs associated with transcriptional silencing in Schizosaccharomyces pombe, RITS, has recently been purified (Verdel et al. 2004). Ago1, the only PAZ-PIWI protein in $S$. pombe, was found in the complex in addition to a chromodomain protein, Chp1, and a novel protein, Tas3.

A connection between RNAi, histone methylation, and DNA methylation in some cases of transposon and transgene silencing in plants has recently been established. It was first demonstrated by Wassenegger that RNA-induced silencing in plants often results in DNA methylation (Wasseneger et al. 1994). Later, dsRNA targeting the promoter region of transgenes in Arabidopsis and tobacco was shown to induce transcriptional silencing and DNA methylation (Mette et al. 2000). Members of the conserved gene families implicated in RNAi, argonaute4 (ago4), dicer-like3 (dc13), and RNA-dependent RNA polymerase2 (rdr2), have been shown to be respon- 
sible for initiation of silencing on the transcriptional level in plants (Zilberman et al. 2003; Chan et al. 2004; Xie et al. 2004).

The importance of the RNAi pathway for silencing of transgenes at the level of chromatin in Drosophila was recently demonstrated. Mutations in two genes encoding PAZ-PIWI proteins piwi and aubergine, as well as in the spindle-E gene encoding a DEAD-motif RNA helicase, resulted in a reduction in $\mathrm{H} 3-\mathrm{K} 9$ methylation and delocalization of HP1 and HP2 (Pal-Bhadra et al. 2004).

It is likely that transcriptional mechanisms contribute to the various silencing events involving repetitive elements in Caenorhabditis elegans. It was first recognized in C. elegans that RNAi is required for silencing of transposons (Ketting et al. 1999; Tabara et al. 1999). Additional examples of silencing of repetitive elements in $C$. elegans include cosuppression (Dernburg et al. 2000; Ketting and Plasterk 2000) and transgene silencing (Kelly et al. 1997). These silencing processes occur predominantly in the germline and are distinguished from other RNAi silencing by the lack of requirement for $r d e-1$ (Dernburg et al. 2000; Ketting and Plasterk 2000). The PAZ-PIWI protein Rde-1 was first shown to play an essential role in RNA silencing in C. elegans (Tabara et al. 1999). There are 24 PAZ-PIWI domain proteins and four RdRPs (Ego-1, Rrf-1, Rrf-2, and Rrf-3) in C. elegans, but thus far, none have been confirmed to be involved in the initiation of transcriptional silencing.

Silencing of repetitive transgenic arrays in the germline of C. elegans is stable and is inherited in an epigenetic fashion due to maintenance of the chromatin state (Kelly et al. 1997; Strome et al. 2001). This process has also been shown to be temperature dependent with stronger silencing observed at lower temperatures $\left(16^{\circ} \mathrm{C}\right.$ and $20^{\circ} \mathrm{C}$ ) as compared with $25^{\circ} \mathrm{C}$ (Strome et al. 2001). Homologs of Polycomb Group genes, mes-2 and mes-6, play a role in this process (Kelly and Fire 1998). Hpl-2, one of two C. elegans HP1 homologs, has been recently implicated in germline transgene silencing (Couteau et al. 2002). Also, inactive transgene arrays have been as- sociated with H3-K9 methylation (Kelly et al. 2002). All of this is consistent with silencing at the level of transcription.

There are different responses to repetitive arrays in the soma and in the germline of C. elegans. For several transgenes with ubiquitous expression patterns, strong expression has been observed in all somatic lineages, while expression in the germline is stably silenced (Kelly et al. 1997). Knight and Bass have recently demonstrated that dsRNA is produced from the repetitive arrays of somatic transgenes and that this RNA is edited by adenosine deaminases (ADARs) (Knight and Bass 2002). Surprisingly, they found that somatic transgenes are silenced in worms with mutations in the ADAR-encoding genes, $a d r-1$ and $a d r-2$, and that this silencing is dependent on rde-1. Evidence suggests that ADAR proteins modify dsRNA, suppressing its ability to generate RNAi activities. Thus, adr-1 and adr-2 mutant backgrounds represent conditions hypersensitive for RNAi silencing. Other conditions, which are known to enhance RNAirelated processes, include mutations in rrf-3 gene (Simmer et al. 2002), probably by reducing competition for substrates for Rrf-1, and, for silencing of transgenes in the germline, culturing animals at lower as opposed to higher temperatures.

Here, we describe silencing of a somatic transgene in C. elegans induced by feeding of Escherichia coli expressing RNAs homologous to a portion of the transgene and the backbone of the repetitive array. This silencing targets pre-mRNA and corresponds to a decrease in the association of RNA polymerase II and acetylated histones with the transgenic array. We refer to this phenomenon as RNAi-induced Transcriptional Gene Silencing, or RNAi-TGS. RNAi-TGS is dependent on the RNAi pathway genes, rde-1, rde-4, rrf-1, and also on the hpl-2 and alg-1 genes, and is not heritable. Using a candidate RNAi screen, we identified additional genes that affect RNAi-TGS, including genes encoding RNA-binding proteins, Polycomb Group proteins, chromodomain proteins, and potential histone methyltransferases. We also show that transcriptional silencing of the transgenic ar-
Figure 1. Silencing of an elt-2::gfp/LacZ transgene is induced by $\mathrm{L} 4440$ feeding. $(A)$ Structures of the pPD96.04 vector used for constructing the elt-2::gfp/ $\mathrm{LacZ}$ strain, the L4440 feeding vector, and L4440 with deletion of the LacZ sequence. The backbone sequence $(2 \mathrm{~kb})$ and 150-bp LacZ fragment are identical in pPD96.04 and L4440. Drawing is not to scale. $(B)$ elt$2:: g f p / L a c Z$ strain not fed with L4440 (top), and elt$2:: g f p / L a c Z$ fed with L4440 vector (middle), and with L4440- $\Delta$ LacZ vector (bottom). Strains were grown at $20^{\circ} \mathrm{C}$.
A

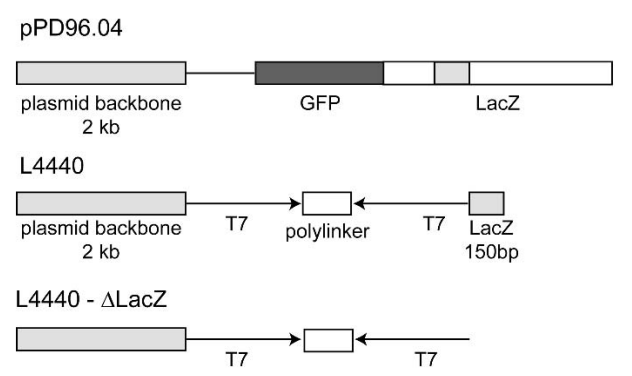

B

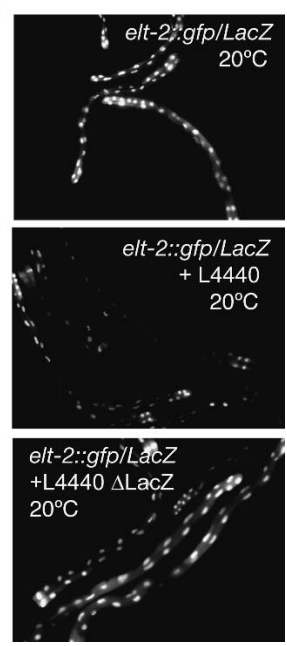


ray occurs spontaneously in the rrf-3 mutant at $16^{\circ} \mathrm{C}$ and is dependent on $r d e-1$. These data provide evidence for a connection between RNAi and transcriptional gene silencing at the chromatin level in C. elegans.

\section{Results}

Feeding induced homology-dependent silencing of the elt-2::gfp/LacZ transgene

Initiation of RNAi by feeding C. elegans dsRNA-expressing bacteria is a common technique (Timmons and Fire 1998). This method uses a KS+-based vector, L4440, containing two T7 promoters flanking a polylinker (Fig. 1A). Any sequence cloned between the T7 promoters will be transcribed into dsRNA upon induction of $\mathrm{T} 7$ polymerase production in bacteria (Timmons and Fire 1998).

In order to study cell division control in C. elegans, we used an elt-2::gfp/LacZ transgenic strain expressing GFP in intestinal nuclei (Fukushige et al. 1998). Our studies included extensive utilization of RNAi by feeding, and we serendipitously discovered that elt-2::gfp/LacZ expression in intestinal nuclei is silenced upon feeding of dsRNA-expressing bacteria regardless of the sequence inserted in the L4440 vector (Figs. 1B, 2A, 3). This silencing was observed in L4 and adult worms fed on L4440 containing bacteria from the time of hatching. Normally, adult worms were put on bacterial plates and their progeny evaluated for silencing. Typically, $80 \%-100 \%$ of 50-200 progeny worms exhibited silencing, with GFP expression reduced to an almost undetectable level in the middle portion of the intestine (Figs. 1B, 3). Surpris- ingly, this silencing was not dependent on a particular gene sequence cloned into L4440 vector. In fact, the empty vector also successfully induced silencing (Figs. 1B, 2A).

We suspected that sequence homology between the transgene and the L4440 vector was responsible for the observed silencing. In C. elegans, transgenic strains are made by injection of plasmid DNA into the germline of adult hermaphrodites (Mello et al. 1991). This plasmid DNA is spontaneously arranged into extrachromosomal multicopy arrays or can be integrated into the genome after irradiation. The elt-2::gfp/LacZ transgenic strain was made using a construct based on the pPD96.04 plasmid from the Fire lab (Fig. 1A) and integrated into the $\mathrm{X}$ chromosome (Fukushige et al. 1998). We looked for possible sequence homology in the backbones of pPD96.04 and L4440 and found that they share a 2-kb identity in the region located immediately adjacent to the L4440 polylinker (Fig. 1A). Also, L4440 contains a 150-bp portion of LacZ sequence adjacent to the other side of the polylinker (Fig. 1A). All plasmids used for making transgenic strains are highly likely to contain sequences identical to those of the L4440 backbone, such as that of the ampicillin resistance gene; however, nonspecific silencing of transgenes by the L4440 feeding vector was not observed in most transgenic lines tested (Table 1).

Since the elt-2::gfp/LacZ transgene is expressing a GFP/LacZ in-frame fusion and its mRNA can be targeted for degradation by a small amount of LacZ dsRNA introduced with L4440, we hypothesized that the 150-bp LacZ gene portion in the L4440 vector might play a crucial role in silencing through the RNAi mechanism. We
A
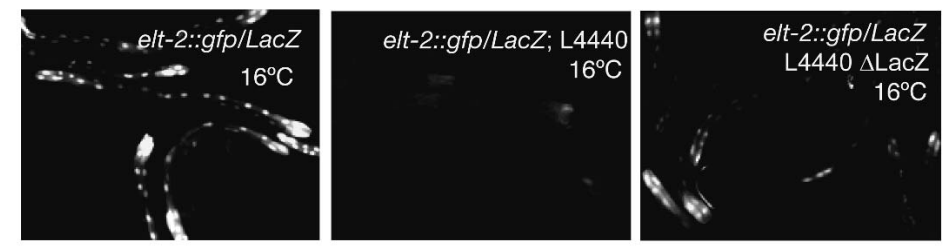

B

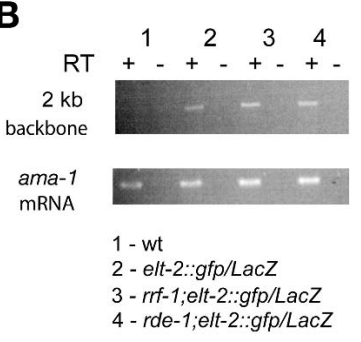

C
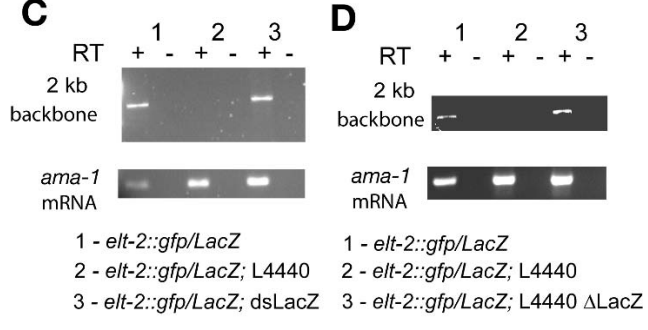

E

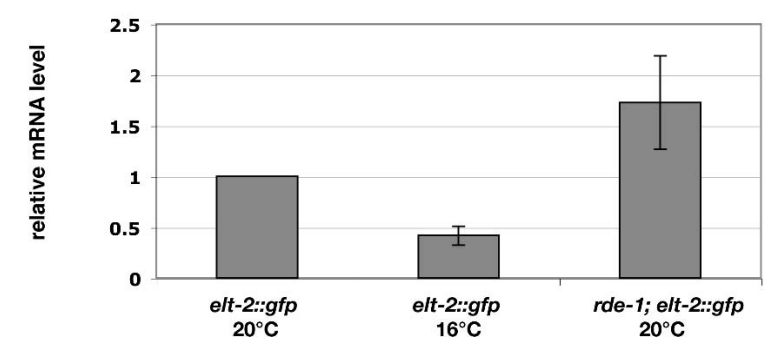

Figure 2. The common vector backbone sequence plays a role in L4440-dependent silencing of elt$2:: g f p / L a c Z$ transgene. (A, left) elt-2::gfp/LacZ strain not exposed to $\mathrm{L} 4440$ at $16^{\circ} \mathrm{C} ; 100 \%$ of the observed worms express GFP. (Middle) elt-2::gfp/ $\mathrm{LacZ}$ worms on $\mathrm{L} 4440$ at $16^{\circ} \mathrm{C} ; 100 \%$ of the observed worms have no GFP expression or very weak expression. (Right) $80 \%-100 \%$ of elt-2::gfp/LacZ worms on $\mathrm{L} 4440-\Delta \mathrm{LacZ}$ at $16^{\circ} \mathrm{C}$ have weak GFP expression. $(B-D)$ RT-PCR-detecting transcript from 2-kb backbone sequence in elt-2::gfp/LacZ strains; $2-\mathrm{kb}$ backbone RNA is not detected in worms silenced by $\mathrm{L} 4440(C, D$, lane 2). ama-1 mRNA is shown as a control for RNA samples. $(E)$ Quantification of the relative levels of $g f p / L a c Z$ mRNA in wild-type transgenic worms at $20^{\circ} \mathrm{C}$ and $16^{\circ} \mathrm{C}$, and rde-1(ne300) worms by real-time RT-PCR; ama-1 expression was used for internal reference. Mean values and ranges of the relative LacZ/ama-1 ratios based on three real-time RT-PCR trials are shown. 
Grishok et al.

Figure 3. L4440-induced silencing of elt-2::gfp/LacZ is dependent on dcr-1, alg-1/2, and hpl-2. The elt$2:: g f p / L a c Z$ strain was fed on L4440 with cloned fragments of genes indicated above each image. Strains were grown at $20^{\circ} \mathrm{C}$.
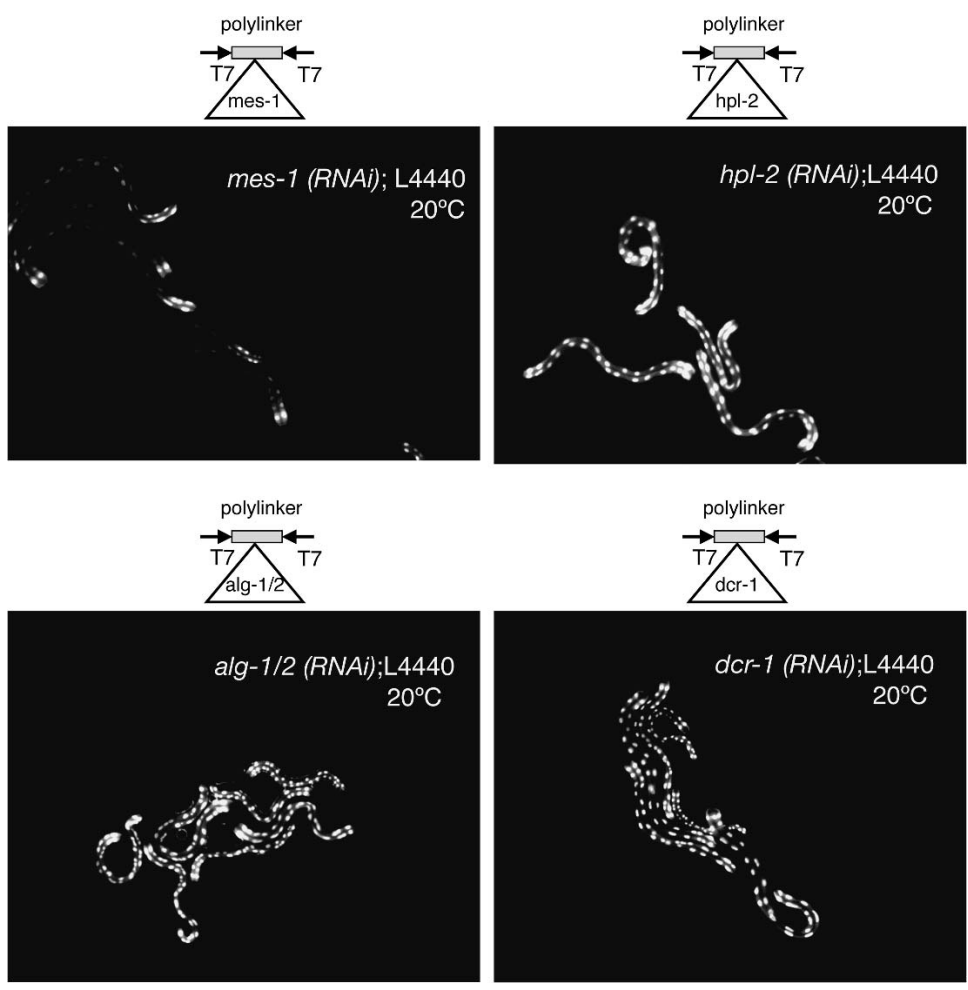

deleted the LacZ sequence from the feeding vector (L4440, $\Delta$ LacZ; Fig. 1A) and observed that efficient silencing was dependent on this portion of the vector (Fig. $1 \mathrm{~B}$, cf. middle and lower panels). Among the other GFP transgenic strains tested, the only strain silenced upon L4440 feeding, myo-3:: gfp/LacZ, also contained an GFP/ LacZ fusion (Table 1). Another LacZ transgenic strain, unc-54::LacZ, was silenced upon L4440 feeding (Table 1 ), supporting the correlation between the presence of a LacZ sequence in the transgene and its susceptibility to silencing by L4440.

Table 1. Strains tested for silencing induced by L4440 feeding

\begin{tabular}{|c|c|c|c|}
\hline Strain & $\begin{array}{l}\text { Repetitive } \\
\text { array or } \\
\text { single copy }\end{array}$ & $\begin{array}{l}\text { Silencing } \\
\text { by L4440 }\end{array}$ & Strain reference \\
\hline elt-2::gfp/LacZ & $\begin{array}{l}\text { Repetitive, } \\
\text { integrated }\end{array}$ & Yes & $\begin{array}{l}\text { Fukushige } \\
\text { et al. (1998) }\end{array}$ \\
\hline pes-10::gfp & $\begin{array}{l}\text { Repetitive, } \\
\text { integrated }\end{array}$ & No & $\begin{array}{l}\text { Montgomery } \\
\text { et al. (1998) }\end{array}$ \\
\hline unc-119::gfp & Repetitive & No & DP 132 \\
\hline myo-3::gfp/LacZ & Repetitive & Yes & PD 4251 \\
\hline pie-1::H2B/gfp & Single copy & No & AZ 212 \\
\hline pie-1::tubulin/gfp & Single copy & No & AZ 244 \\
\hline cye-1::gfp & Repetitive & No & KM 32 \\
\hline$c k i-1:: g f p$ & $\begin{array}{l}\text { Repetitive, } \\
\text { integrated }\end{array}$ & No & VT 825 \\
\hline unc-54::LacZ & Repetitive & Yes & PJ 1044 \\
\hline myo-2::LacZ & Repetitive & No & PD 8251 \\
\hline
\end{tabular}

The role of the plasmid backbone sequence in L4440-induced silencing

Transgenic arrays are known to be prone to silencing in the $C$. elegans germline. When worms are maintained at $16^{\circ} \mathrm{C}-20^{\circ} \mathrm{C}$, the transgenes are mostly silenced during the third generation after transformation, while worms cultured at $25^{\circ} \mathrm{C}$ maintain strong expression of the transgenes for many generations (>100) (Strome et al. 2001).

In order to test whether feeding-induced silencing was temperature dependent, we performed experiments at $16^{\circ} \mathrm{C}$. Interestingly, the vector construct lacking the LacZ sequence was able to induce weak silencing of the elt-2::gfp/LacZ strain at $16^{\circ} \mathrm{C}$ (Fig. $2 \mathrm{~A}$, cf. left and right panels). We predicted that this silencing might be due to the $2-\mathrm{kb}$ sequence homology between the backbone of the transgene incorporated into the worm's genomic DNA and the backbone of the feeding plasmid. We tested whether the plasmid backbone sequence was transcribed in transgenic worms by RT-PCR, and indeed found that the whole 2-kb region of identity between pPD96.04 and L4440 was transcribed (Fig. 2B-D). This RNA was undetectable when the transgene was silenced by L4440 feeding, but still present in worms where GFP/LacZ expression was silenced by soaking in LacZ dsRNA (Fig. 2C). Silencing of the backbone RNA by feeding correlated with the level of silencing of GFP/LacZ transgene. For example, feeding the L4440 vector containing the LacZ fragment induced stronger silencing of both GFP/LacZ transgene (Fig. 2A) and the backbone RNA (Fig. 2D) as compared with feeding the vector with the LacZ portion deleted. Therefore, the presence of the LacZ fragment in 
L4440 increased the degree of silencing of the transgenic array over that induced through transcription of the plasmid backbones.

We next investigated possible background silencing of the transgenic array in the elt-2::gfp/LacZ strain. Transgenes in the somatic tissue are not typically silenced to the same extent as transgenes in the germline. However, they could still be subject to some repression by RNAi or/and chromatin-related mechanisms. We used realtime RT-PCR to determine relative mRNA expression levels of $g f p / L a c Z$ transgene in the wild-type background and in the RNAi-deficient background of an rde-1 mutant and found that expression was elevated by twofold in rde-1 (Fig. 2E). This suggests that somatic transgene expression in this line is suppressed by an RNAi-related process. Furthermore, transgene mRNA levels were reduced in worms cultured at $16^{\circ} \mathrm{C}$ (Fig. 2E). Again, this is consistent with an endogenous process limiting expression of the transgene. Temperature dependence of L4440-induced silencing therefore probably reflects a stimulation of this endogenous process.

\section{Silencing depends on RNAi pathway, Alg-1, and Hpl-2}

We tested whether RNA feeding-induced silencing of $e l t$ $2:: g f p / L a c Z$ in this system is dependent on the RNAi pathway. The elt-2::gfp/LacZ transgenes were completely resistant to silencing when crossed into RNAideficient backgrounds, rde-1(ne300), rde-4(ne299), and rrf-1 (pk1417) (Table 3, below).

We next tested whether the L4440 vector could prevent silencing of elt-2::gfp/LacZ transgene if the vector was designed to silence a gene in the RNAi pathway, i.e., contained a portion of the gene cloned between the $\mathrm{T} 7$ promoters (Fig. 3). In this case, the vector simultaneously initiates elt-2::gfp/LacZ silencing (vector induced) and also initiates RNAi silencing of the gene corresponding to the segment between the $\mathrm{T} 7$ promoters. If this latter gene is critical for the pathway leading to the transgene silencing, the vector-induced silencing will be suppressed. Using this technique, we observed that $d c r-1$ is required for the silencing process (Fig. 3), which is consistent with involvement of the RNAi pathway. Many L4440 vectors containing portions of randomly chosen genes, like mes-1 (Fig. 3), induced the same level of elt-2::gfp/LacZ silencing as an empty L4440 vector, and thus, these genes are probably not required for silencing of the transgenic array. More than 50 constructs, which supported silencing induced by feeding, are listed in Supplementary Table 1.

We also observed that alg-1 and alg-2 genes, which are not required in the classical RNAi pathway, are required for elt-2::gfp/LacZ silencing process (Fig. 3). Alg-1 is a PAZ-PIWI family gene shown to be essential for miRNA pathways (Grishok et al. 2001). The requirement for alg-1 in elt-2::gfp/LacZ silencing was confirmed with alg-1(gk214) deletion mutant generated by the C. elegans Gene Knock-out Consortium (Supplementary Fig. 1A).

Since silencing of elt-2::gfp/LacZ has features of re- peat-induced silencing (such as temperature sensitivity), we investigated whether silencing in this system might occur on a transcriptional level. If silencing of elt-2::gfp/ LacZ by L4440 occurs at the level of chromatin, then it might be sensitive to mutations in proteins known to suppress transcription at this level. We next tested the requirement for Hpl-2, a homolog of the Heterochromatin protein 1 . RNAi of $h p l-2$ by feeding prevented silencing of elt-2::gfp/LacZ in the presence of the feeding vector (Fig. 3). This result was confirmed using a deletion mutant in hpl-2 generated by the C. elegans Gene Knock-out Consortium (Supplementary Fig. 1A). For both alg-1 and hpl-2 deletion mutants, desilencing of the elt-2::gfp/LacZ transgene in mutant backgrounds was more apparent at $16^{\circ} \mathrm{C}$, where feeding-induced silencing is more stringent.

Pre-mRNA is targeted in the feeding-induced elt-2::gfp/LacZ silencing

Early studies of RNAi in C. elegans determined that mature mRNA was targeted during the silencing process (Montgomery et al. 1998). Specifically, the injection of dsRNA resulted in decreases in the levels of mRNA, but levels of the nuclear pre-mRNAs were not significantly repressed (Montgomery et al. 1998). This was confirmed in a Trypanosome system (Ngo et al. 1998). Importantly, an in vitro RNAi system revealed that mature mRNA is degraded during RNAi (Tuschl et al. 1999).

If silencing of the elt-2::gfp/LacZ transgene by L4440 vector is indeed at the stage of transcription (RNAiTranscriptional Gene Silencing) and is distinct from traditional RNAi (RNAi - Post-Transcriptional Gene Silencing), it should lead to a decrease in the level of target pre-mRNA, while RNAi-PTGS should have no effect on the level of pre-mRNA. To test this, we soaked worms in a LacZ dsRNA solution, a technique similar to feeding (Tabara et al. 1998), to induce RNAi-PTGS.

The $g f p / L a c Z$ fusion transgene in the pPD96.04 construct contains numerous small introns, which allows detection of both pre-mRNA and mRNA by RT-PCR. Two pairs of primers were designed; one pair, specific for exons spanning two introns, produced a 357-bp product from the mature mRNA and a 458 -bp product from premRNA (Fig. 4A, top); the second pair, specific for the two introns and spanning an exon, detected only an 373-bp product from the pre-mRNA (Fig. 4A, middle). RT-PCRs were performed on RNA obtained from a nonsilenced elt-2::gfp/LacZ strain, a strain silenced by the feeding vector (L4440) and a strain silenced by soaking in LacZ dsRNA (dsLacZ). Using exon-specific primers, we observed that the level of $g f p / L a c Z$ pre-mRNA decreased along with the level of mature mRNA in worms silenced by feeding (Fig. 4A, top, lane 5). In soaked worms, premRNA was detected while mRNA levels decreased (Fig. 4A, top, lane 7). Using intron-specific primers, we could not detect $g f p / L a c Z$ pre-mRNA in the worms silenced by feeding (RNAi-TGS) (Fig. 4A, middle, lane 5), but in worms silenced by soaking (RNAi-PTGS) pre-mRNA was still detected (Fig. 4A, middle, lane 7). 
Grishok et al.

Figure 4. RT-PCR analysis of pre-mRNA and mRNA levels during L4440-induced silencing of elt-2::gfp/ LacZ. (A) RT-PCR of $g f p / L a c Z$ transgene; amplification with exon-specific primers (top) detects products from the mature mRNA (357 bp) and pre-mRNA (458 bp); amplification with intron-specific primers (middle) detects a product of 373-bp; ama-1 mRNA RT-PCR detecting a 236-bp product is shown as control (bottom). (B) Quantification of the relative levels of $g f p / L a c Z$ mRNA and $g f p / L a c Z$ pre-mRNA shown in $A$ by realtime RT-PCR; ama-1 expression was used for internal reference. Mean values and ranges of the relative $L a c Z /$ ama-1 ratios based on two real-time RT-PCR trials are shown.
A

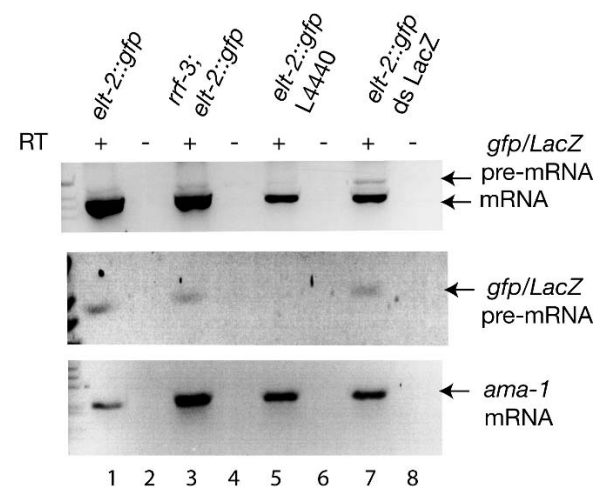

B
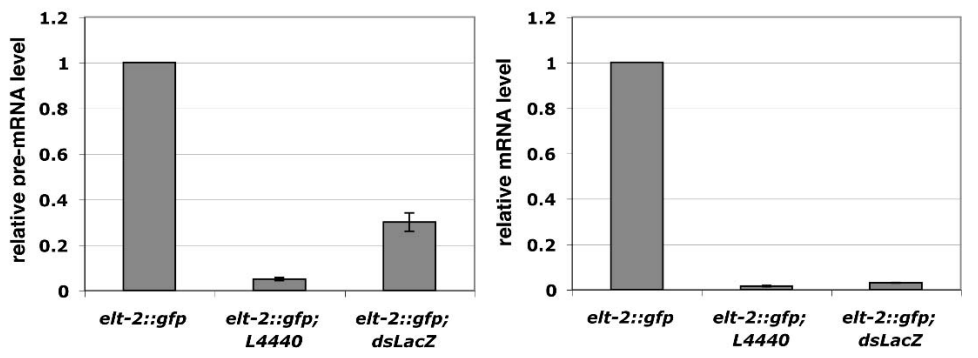

To quantify the observed effects, we used additional sets of $g f p / L a c Z$ exon-specific and intron-specific primers in real-time RT-PCR (Fig. 4B). While the levels of both pre-mRNA and mRNA were dramatically reduced (by 20- and 50-fold, respectively) during RNAi-feeding, soaking in LacZ dsRNA led to reduction in mRNA level by 30 -fold and reduction in pre-mRNA by only threefold. This slight reduction in pre-mRNA level during soaking in LacZ dsRNA might indicate that these conditions also weakly stimulate transcriptional silencing. These data indicate that elt-2::gfp/LacZ silencing induced by feeding vector occurs at the pre-mRNA stage, and thus, is distinct from RNAi-PTGS. Additional experiments illustrating a decrease in elt-2::gfp/LacZ pre-mRNA levels during silencing induced by the L4440 vector are presented in Supplementary Figure 2.

\section{RNAi-TGS silencing in rrf-3 background}

RdRPs have been implicated in homology-dependent silencing in plants, fungi, and nematodes. In C. elegans, ego-1 and rrf-1 are required for RNAi in the germline and soma, respectively (Smardon et al. 2000; Sijen et al. 2001). Another RdRP gene, rrf-3, has been reported to antagonize RNAi (Simmer et al. 2002). Therefore, RNAirelated processes are more efficient in the rrf-3 mutant. Consistent with this, we found that feeding-induced silencing of elt-2::gfp/LacZ transgene was stronger in an rrf-3 mutant background as compared with the wild-type background. For example, L4440 vectors containing the LacZ fragment and those lacking this homology to the $g f p / L a c Z$ transgene significantly reduced both the $g f p /$ LacZ mRNA and pre-mRNA levels in this genetic background (Fig. 5C).
Interestingly, we found that expression of the elt2::gfp/LacZ transgene was almost completely silenced in an $r r f-3$ background at $16^{\circ} \mathrm{C}$ even without feeding on the $\mathrm{L} 4440$ vector (Fig. 5A). While the level of transgene expression is reduced at $16^{\circ} \mathrm{C}$ in wild-type worms (Fig. 2D), the effect is much more dramatic in rrf-3 mutant. These results indicate that Rrf-3, similarly to Adr- 1 and Adr-2, prevents silencing of the repetitive transgenes in somatic tissues of the wild-type worms. It is likely that temperature-dependent silencing of the elt-2::gfp/LacZ transgene in $r r f-3$ background is mechanistically similar to the silencing induced by feeding discussed above. During this temperature-dependent silencing, not only was the level of $g f p / L a c Z$ pre-mRNA significantly reduced (Fig. 5B, lane 3), but also the 2-kb backbone-specific RNA was undetectable by RT-PCR (Fig. 5B). Silencing in rrf-3 (pk1426) background also depended on the RNAi pathway gene rde-1(ne300), (Fig. 5A, cf. middle and bottom panels). Silencing at the level of transcription is frequently maintained by localization of histone deacetylase activities. Thus, we determined whether culturing worms in the presence of histone deacetylase (HDAC) inhibitors would result in suppression of this silencing. This was indeed the case (Table 2). All of this is consistent with RNA-induced transcriptional silencing (RNAi-TGS).

Silencing of elt-2::gfp/LacZ is accompanied by a decrease in histone $\mathrm{H} 4$ acetylation

To further confirm silencing of elt-2::gfp/LacZ at the level of transcription, we performed chromatin immunoprecipitation (ChIP) experiments using antibodies against acetylated histone $\mathrm{H} 4$ and antibodies against the 
A

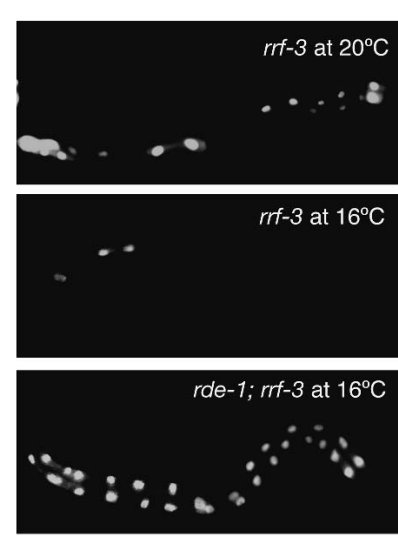

C

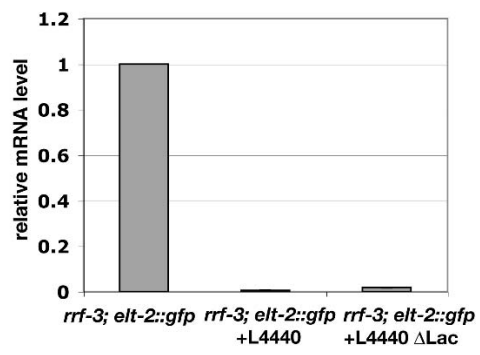

B

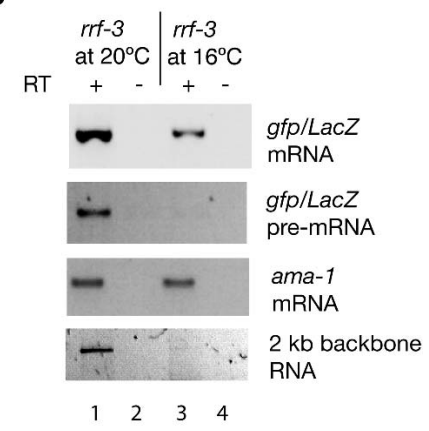

Figure 5. Silencing of elt-2::gfp/LacZ in an rrf-3 background. (A) rrf-3;elt-2::gfp/LacZ at $20^{\circ} \mathrm{C}($ top); rrf-3; elt$2: \because g f p / L a c Z$ at $16^{\circ} \mathrm{C}$ (middle); rde-1; rrf-3;elt-2::gfp/ LacZ at $16^{\circ} \mathrm{C}$ (bottom). (B) RT-PCR of $g f p / L a c Z$ transgene; amplification with exon-specific primers (top), intron-specific primers (middle); ama-1 control (lower middle), and primers specific for the 2-kb backbone sequence (bottom). (C) Real-time RT-PCR quantification of the relative levels of $g f p / L a c Z$ mRNA and $g f p / L a c Z$ pre-mRNA during silencing induced by feeding the L4440 or L4440 $\Delta$ LacZ vectors; ama-1 expression was used for internal reference. Mean values and ranges of the relative LacZ/ama-1 ratios based on two real-time RT-PCR trials are shown.

C-terminal domain (CTD) of polymerase II. Acetylated histones $\mathrm{H} 3$ and $\mathrm{H} 4$ typically associate with actively transcribed genes, while histone deacetylation correlates with transcriptional silencing.

We compared the level of histone $\mathrm{H} 4$ acetylation at the elt-2::gfp/LacZ locus in rrf-3;elt-2::gfp/LacZ strain cultured at $20^{\circ} \mathrm{C}$ with or without feeding with the L4440 silencing vector, and detected a decrease in histone acetylation under the silenced conditions (Fig. 6A,B). We tested the association of acetylated histone $\mathrm{H} 4$ with elt-2::gfp/LacZ DNA at two different regions of the transgene using two different sets of primers (Fig. 6A, top and middle). The set of primers used in the middle panel of Figure 6A is the same as in the middle panel of Figure 4A. We also tested the association of acetylated histone $\mathrm{H} 4$ with the 2-kb fragment of the backbone DNA and detected a decrease upon silencing. As an internal control, we assayed the acetylation levels of histone $\mathrm{H} 4$ at the act-3 locus, a transcriptionally active actin gene. As expected, act-3 association with acetylated $\mathrm{H} 4$ did not change upon feeding (Fig. 6A). We did not detect DNA precipitation by the agarose beads with- out antibody (Fig. 6A) or with several nonspecific antibodies in independent ChIP experiments (data not shown).

We quantified the ChIP results presented in Figure 6A and several additional experiments by real-time PCR using a set of primers amplifying a short DNA segment (Fig. 6A, top). Real-time PCR analysis indicated an average 2.5 -fold decrease in the relative ratios of elt-2::gfp/ LacZ transgene DNA to act-3 DNA when chromatin was precipitated with antibody to acetylated histone $\mathrm{H} 4$ under nonsilenced and silenced conditions, respectively (Fig. 6B, top). We detected a similar decrease in histone acetylation when an L4440 vector lacking LacZ fragment was used for the induction of silencing (Fig. 6B, top), indicating a common underlying mechanism. ChIP experiments with polymerase II CTD antibodies also detected less polymerase associated with the elt-2::gfp/ LacZ under silenced conditions (Fig. 6B, bottom). These results strongly indicate that transcription is reduced at the elt-2::gfp/LacZ locus.

We next tested whether histone $\mathrm{H} 4$ acetylation is altered in RNAi pathway mutant backgrounds affecting

Table 2. Effect of histone deacetylase inhibitors on rrf-3; elt-2::gfp silencing at $16^{\circ} \mathrm{C}$

\begin{tabular}{|c|c|c|c|c|}
\hline $\begin{array}{l}\text { GFP } \\
\text { expression }\end{array}$ & $\begin{array}{l}\text { No HDAC } \\
\text { inhibitor }\end{array}$ & TSA $(4 \mu \mathrm{M})$ & $\begin{array}{l}\text { Apicidin } \\
(2 \mu M)\end{array}$ & $\begin{array}{c}\text { n-butyrate } \\
\text { (6.7 mM) }\end{array}$ \\
\hline Expression in more than 5 nuclei & $2 / 40^{\mathrm{a}}(5 \%)$ & $26 / 41(63 \%)$ & $21 / 42(50 \%)$ & $32 / 40(80 \%)$ \\
\hline Complete silencing & $15 / 40(38 \%)$ & $0 / 41(0 \%)$ & $1 / 42(2 \%)$ & $0 / 40(0 \%)$ \\
\hline
\end{tabular}

${ }^{\mathrm{a}}$ Fraction of worms showing phenotype of a total number scored. 
Grishok et al.

A

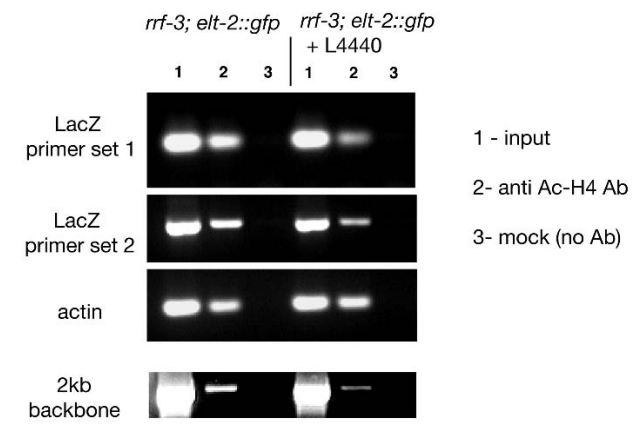

Figure 6. elt-2::gfp/LacZ silencing is associated with decrease in histone $\mathrm{H} 4$ acetylation and polymerase II association. (A) ChIP with anti-acetyl-H4 antibodies was performed on extracts from $r r f-3$; elt-2::gfp strain with (right) and without (left) L4440 feeding. PCR products were amplified with primers specific for the $g f p /$ LacZ transgene (top), 2-kb backbone sequence (bottom) or act-3 gene (middle) as an internal control. (Lane 1) DNA purified from $1 / 40$ of input material was used. (Lane 2) DNA bound to agarose A beads with anti-acetyl-H4 antibodies. (Lane 3) DNA bound to agarose A beads without antibody. $(B, C)$ Real-time PCR quantification of the relative amounts of $g f p / L a c Z$ DNA precipitated by anti-acetyl-H4 antibodies or 8WG16 Pol II antibodies at indicated conditions, act-3 was used as internal reference. Mean values and ranges of the relative LacZ/actin ratios from two to three independent experiments are shown.

B
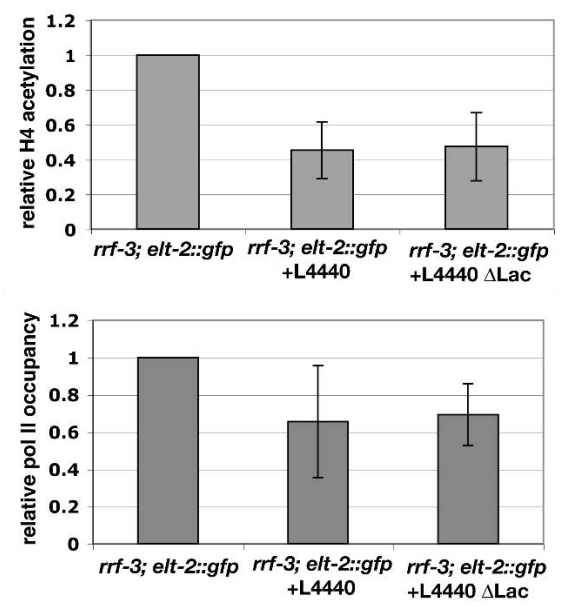

C
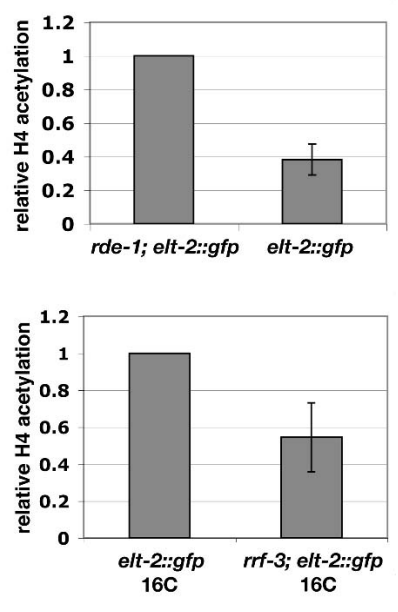

elt-2::gfp/LacZ expression. Indeed, the level of $\mathrm{H} 4$ acetylation at elt-2::gfp/LacZ locus was higher in the rde-1 mutant as compared with wild-type transgenic strain (Fig. 6C, top), and it was lower in the rrf-3 mutant at $16^{\circ} \mathrm{C}$ as compared with wild-type worms cultured under the same conditions (Fig. 6C, bottom). These results indicate that RNAi-related processes affects background elt-2::gfp/LacZ expression at the chromatin level.

\section{Candidate screen for effectors of RNAi-TGS}

Induction of elt-2::gfp/LacZ transcriptional silencing by feeding of the L4440 vector represents a convenient system, where the connection between RNAi and subsequent chromatin-based silencing can be studied. Since fragments of nearly all C. elegans genes have been cloned into the L4440 vector for the purpose of large-scale phenotypic analysis (Kamath and Ahringer 2003), this resource represents a useful tool for finding genes that affect silencing induced by the L4440 vector using the strategy described earlier in this work.

Approximately 100 genes known to be involved in RNAi or transgene silencing by previous studies, as well as candidate genes with the potential to be involved in RNAi-TGS, including histone deacetylases, potential histone methyltransferases, chromodomain-containing genes, and genes involved in chromatin remodeling (Supplementary Table 1) were simultaneously tested for an effect on GFP silencing induced by the $\mathrm{L} 4440$ vector in a wild-type and rrf-3 (pk1426) background. Silencing was stronger in rrf-3 mutants than in wild-type worms (Supplementary Fig. 3), and it was generally difficult to relieve elt-2::gfp/lacZ silencing in the rrf-3 background. Thirty-seven percent of the candidates affected L4440induced silencing in a wild-type background. A subset of those, comprising $12 \%$ of the candidate genes, affected L4440-induced silencing in rrf-3 mutant worms.

This screen confirmed that known RNAi pathway genes were involved in silencing; see rsd-3, rsd-6, tsn-1, mut-16, and smg-5 in Table 3. Some of the genes affecting silencing in this system overlapped with a set of genes involved in transposon silencing, most notably the F55F8.3 gene, which encodes a protein with WD domain and G- $\beta$ repeats (Vastenhouw et al. 2003). The tsn-1 gene implicated in Drosophila RNAi and miRNA pathways (Caudy et al. 2003) also affected silencing in this system. In agreement with the possible implication of histone modifications in the silencing process, we found that histone deacetylase $h d a-2$, and genes encoding potential SET-domain methyltransferases, set-1, set-2, and T21B10.5 are also involved. We identified the HP1 homolog, hpl-2, to be important for RNAi-TGS earlier in this work; we found that another HP1 homolog, hpl-1, also affected silencing, but to a lesser degree. Beside Hpl-1 and Hpl-2, two other chromodomain proteins, Mrg-1 (Fujita et al. 2002) and T09A5.8 are also involved 
Table 3. Genes affecting RNAi-TGS of elt-2::gfp/LacZ

\begin{tabular}{|c|c|c|c|c|}
\hline \multicolumn{5}{|c|}{ Genes involved in RNAi } \\
\hline Gene & Name & Domain/function & Desilencing in WT & $\begin{array}{l}\text { Desilencing } \\
\text { in rrf-3 mutant }\end{array}$ \\
\hline B0379.3 & mut-16 & Chromatin organization (Vastenhouw et al. 2003) & ++ & ++ \\
\hline W02D3.8 & smg-5 & Nucleotide binding protein (Domeier et al. 2000) & ++ & -- \\
\hline F16D3.2 & $r s d-6$ & Tudor domain (Tijsterman et al. 2004) & ++ & ++ \\
\hline F10G7.2 & $t s n-1$ & $\begin{array}{l}\text { Tudor domain (Caudy et al. 2003) } \\
\text { dsRNa binding, RNAse III }\end{array}$ & ++ & -- \\
\hline $\mathrm{K} 12 \mathrm{H} 4.8$ & $d c r-1$ & (Grishok et al. 2001; Knight and Bass 2001) & ++ & ++ \\
\hline C34E11.1 & rsd-3 & ENTH domain (Tijsterman et al. 2004) & ++ & -- \\
\hline K08H10.7 & rde-1 (ne300) & PAZ/PIWI domain (Tabara et al. 1999) & +++ & ND \\
\hline T20G5.11 & rde-4 (ne299) & dsRNA binding (Tabara et al. 2002) & +++ & ND \\
\hline F26A3.8 & $r r f-1(p k 1417)$ & RdRP (Sijen et al. 2001) & +++ & ND \\
\hline \multicolumn{5}{|c|}{ Genes implicated in transposon silencing (Vastenhouw et al. 2003) } \\
\hline K07A12.3 & asg-1 & mitochondrial ATP synthase g subunit & ++ & -- \\
\hline F55F8.3 & & G-protein beta WD-40 repeat, similar to U4/U6 SNP & ++ & ++ \\
\hline W01B11.3 & & snoRNA binding & ++ & ++ \\
\hline ZK858.7 & & Translation initiation factor & ++ & -- \\
\hline Y54E5A.4 & $n p p-4$ & Nucleoporin FG repeat & ++ & + \\
\hline Y106G6H.2 & pab-1 & Poly(A) binding protein & ++ & -- \\
\hline F35G12.10 & $a s b-1$ & Mitochondrial ATP synthase & ++ & -- \\
\hline M01F1.3 & & Lipoic acid synthase, radical SAM & ++ & ++ \\
\hline F37C12.4 & $r p l-36$ & Ribosomal protein L36 & ++ & ++ \\
\hline C08F8.2 & & ATP dependent helicase activity & ++ & -- \\
\hline D2096.8 & & Nucleosome assembly protein & ++ & -- \\
\hline \multicolumn{5}{|c|}{ Genes with a chromatin-related function } \\
\hline C08B11.2 & hda-2 & Histone deacetylase (Pothof et al. 2003) & ++ & -- \\
\hline $\mathrm{C} 04 \mathrm{~A} 2.3$ & egl-27 & BAH/ELM2 domain (Solari et al. 1999) & ++ & -- \\
\hline T09A5.8 & & Chromo domain & ++ & -- \\
\hline K01G5.2 & hpl-2 & Chromo domain (Couteau et al. 2002) & ++ & -- \\
\hline T26A5.7 & set-1 & SET domain (Terranova et al. 2002) & + & -- \\
\hline C26E6.9 & set-2 & SET domain (Terranova et al. 2002) & ++ & -- \\
\hline T21B10.5 & & Contains Zn-finger, SET domains & + & -- \\
\hline Y43C5A.6 & rad-51 & DNA binding (Takanami et al. 1998) & ++ & -- \\
\hline M04B2.3 & $g f l-1$ & Chromatin binding (Dudley et al. 2002) & ++ & -- \\
\hline K08H2.6 & hpl-1 & Chromo domain (Couteau et al. 2002) & + & -- \\
\hline Y37D8A.9 & $m r g-1$ & Chromo domain (Fujita et al. 2002) & ++ & ++ \\
\hline F54F2.2 & $z f p-1$ & Chromatin/DNA binding (Dudley et al. 2002) & ++ & -- \\
\hline C50E10.4 & sop-2 & SAM domain, Hox gene regulation (Zhang et al. 2004a,b) & ++ & + \\
\hline $\mathrm{C} 25 \mathrm{~A} 1.10$ & dao-5 & Nuclear phosphoprotein, similar to sop-2 (BLAST) & ++ & -- \\
\hline F55F8.4 & & Related to Tas3 (Verdel et al. 2004) & + & -- \\
\hline \multicolumn{5}{|c|}{ Genes involved in RNA binding and/or translational regulation } \\
\hline F18A11.1 & puf-6 & Pumilio/Puf RNA binding (Wickens et al. 2002) & ++ & -- \\
\hline B0273.2 & puf-7 & Pumilio/Puf RNA binding (Wickens et al. 2002) & ++ & -- \\
\hline F48F7.1 & alg-1 & PAZ/PIWI domain (Grishok et al. 2001) & + & -- \\
\hline B0035.12 & & RNA binding region, poly(A) binding & ++ & ++ \\
\hline D1037.1 & & dsRNA binding & ++ & -- \\
\hline \multicolumn{5}{|c|}{ Genes involved in sumoylation } \\
\hline $\mathrm{K} 12 \mathrm{C} 11.2$ & smo-1 & Ubiquitin-like protein & + & -- \\
\hline W02A11.4 & $u b a-2$ & SUMO-activating complex & ++ & + \\
\hline
\end{tabular}

$(+++) 100 \%$ of worms desilenced; (-) 80-100\% of worms completely silenced; $(++)$ 80-100\% of worms desilenced; $(--) 100 \%$ of worms completely silenced; $(+)>50 \%$ of worms desilenced.

(Table 3). We identified two PAZ-PIWI domain proteins, Rde-1 and Alg-1, as effectors in the transcriptional silencing pathway. The other 10 PAZ-PIWI genes tested, including piwi-related genes, prg-1 and prg-2, did not have an effect on silencing (Supplementary Table 1). Finally, we found that the F55F8.4 gene, which encodes a protein related to RITS component Tas3 (Verdel et al. 2004; Supplementary Fig. 4) also affected silencing.

The recent discovery of RNA binding by C. elegans Polycomb Group gene sop-2 (Zhang et al. 2004a) prompted us to test it in this system. Down-regulation of sop-2 by RNAi prevented L4440-induced silencing in 
wild-type and rrf-3 worms (Supplementary Fig. 3, Table 3). Sop-2 might play an important role in connecting the RNAi pathway and chromatin-repressing components in homology-dependent silencing.

We also found that genes important for sumoylation, smo-1 and uba-2, have a role in RNAi-TGS of the transgenic array. Many chromatin repressor proteins, including Sop-2 (Zhang et al. 2004b), require sumoylation for their function.

\section{Discussion}

In this study, we describe a system in C. elegans that leads to somatic transcriptional gene silencing via the RNAi pathway. Prior to this study, a role for RNAi in the initiation of TGS had not been established in C. elegans. Repetitive transgenes in the germline of $C$. elegans are silenced at the transcriptional level (Kelly and Fire 1998). This silencing is maintained across generations and is very stable, making it difficult to study the initiation of the process.

In the silencing of elt-2::gfp/LacZ transgene in the soma by feeding bacteria containing dsRNA, we assume that dsRNA adds to the level of dsRNA produced from the transgenic array and stimulates transcriptional si- lencing (Fig. 7). An increase in the level of secondary siRNAs produced by RdRp also is likely to play a role in this process (Fig. 7). There are numerous lines of evidence that elt-2::gfp/LacZ silencing in the soma is different from RNAi-PTGS and occurs predominantly at the level of transcription. First, this soma transgene silencing depends upon Alg-1, whereas RNAi mediated post-transcriptional silencing does not (Grishok et al. 2001). Second, generation of nuclear intron containing pre-mRNA is inhibited during silencing of the elt-2::gfp/ LacZ transgene, which contrasts with previous results where post-transcriptional gene silencing by RNAi reduced the levels of mRNAs, but not nuclear pre-mRNAs (Montgomery et al. 1998). Third, inhibition of $g f p / L a c Z$ pre-mRNA production is caused by a plasmid containing no homology to the coding region of the $g f p / L a c Z$ transgene. Fourth, the soma transgene silencing was dependent upon heterochromatin factors such as HP1 type proteins. Fifth, treatment of worms with drugs that inhibit histone deacetylases suppressed the silencing of the transgene. Sixth, ChIP assays showed that the silenced soma transgene contained less acetylated histone $\mathrm{H} 4$ protein and less polymerase II than the nonsilenced state. This ensemble of observations strongly indicates that genes can be silenced in the soma of C. elegans at
Figure 7. Schematic model showing a possible mechanism of RNAi-TGS at the elt-2::gfp/LacZ repetitive array. Transcription of the $g f p / L a c Z$ pre-mRNA (green/ blue line) and bidirectional transcription in the repetitive array (black lines) occurs in the transgenic worms. dsRNA produced from the locus would be processed by Dicer, generating siRNAs, which might induce a low level of background silencing of the array. However, silencing of the array is not efficient without additional stimuli. Feeding worms with dsRNA produced from the L4440 vector brings the level of LacZ and backbonespecific siRNA to the threshold level, stimulating chromatin modifications, HP1 localization, and TGS at the locus.

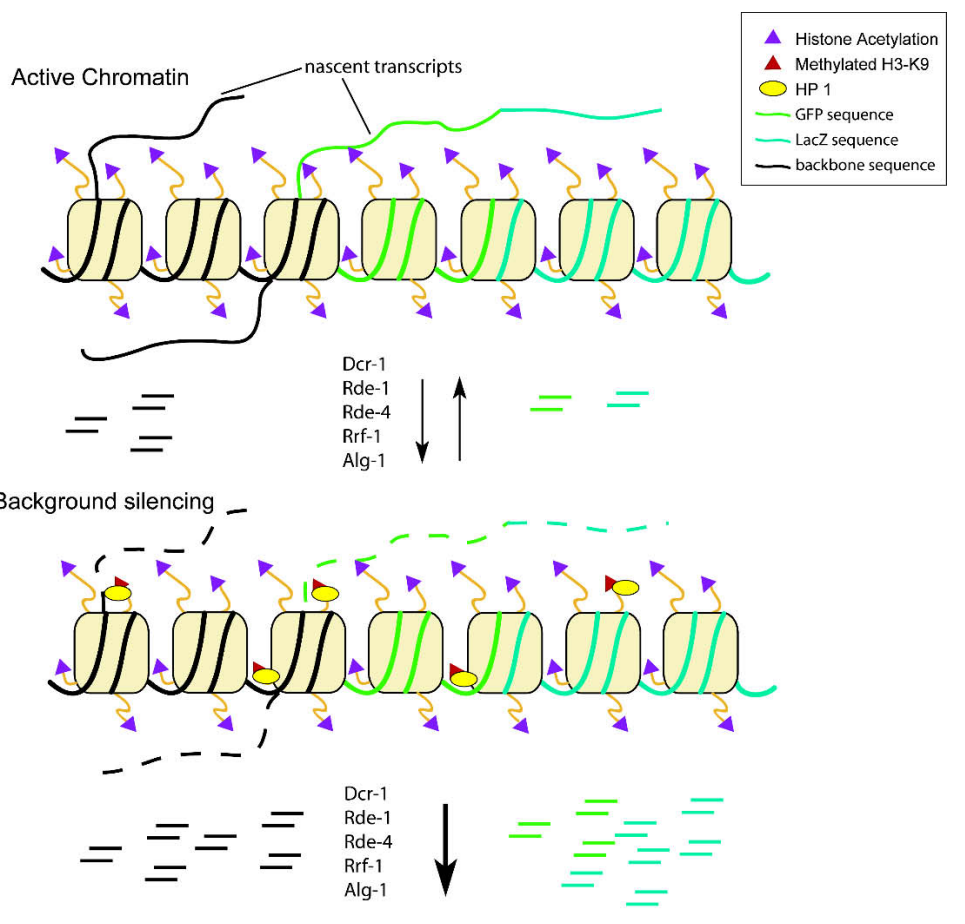

Feeding-induced silencing

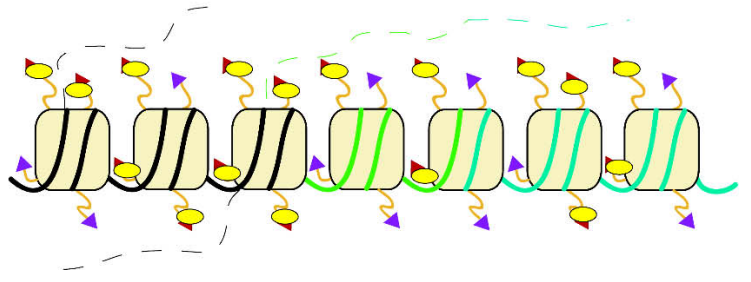


the level of transcription through an RNAi-related process.

The RNA-dependent RNA polymerase $r r f-3$ has been shown to antagonize RNAi processes (Simmer et al. 2002). Since other C. elegans RdRps, Rrf-1, and Ego-1, are essential for RNAi (Smardon et al. 2000; Sijen et al. 2001), Rrf-3 is thought to compete with them for a limited amount of shared components. We demonstrate that in the rrf-3 mutant, the elt-2::gfp/LacZ transgene becomes completely silenced at $16^{\circ} \mathrm{C}$, and this effect depends on Rde-1. Under these conditions, the levels of transgene pre-mRNA and mRNA are greatly reduced in the silenced worms, and this inhibition is reversed if histone deacetylation is suppressed by drug treatment. These results suggest that dsRNA produced from the repetitive transgene can induce transcriptional silencing, and that RdRp activity and the PAZ-PIWI protein Rde-1 are essential for this process.

The RNAi-TGS pathway in the soma of C. elegans is probably similar to the recently described process in $S$. pombe (Noma et al. 2004), where siRNAs guide one or more types of RITS (RNA-induced initiation of transcriptional gene silencing) complexes to modify histones and produce heterochromatin. The requirement for feeding dsRNA in the silencing of the transgene in the soma could reflect the need to generate and amplify siRNAs, perhaps through the action of RNAi-PTGS and RdRp activities on the mRNA from the transgene. However, this is likely to be transient, as the mRNA would disappear as transcriptional silencing proceeds. The active PTGS process in C. elegans is accompanied by the constant production of secondary antisense siRNAs (Sijen et al. 2001), which are readily detectable by Northern blot (A. Grishok and C.C. Mello, unpub.) Using identical methods, we have not been able to detect siRNAs corresponding either to the $L a c Z$ or the backbone vector sequences (data not shown). This is likely due to a much lower abundance of siRNAs during TGS as compared with PTGS. For example, Birchler and colleagues detected siRNAs associated with PTGS of a transgene in Drosophila, but were unable to detect siRNAs when a similar transgene was silenced by TGS (Pal-Bhadra et al. 2002).

Dudley and colleagues (Dudley at al. 2002) have previously suggested that transcriptional regulation occurs during RNAi in C. elegans. They used RNAi to knock down genes known to be important for transcriptional regulation, zfp-1 (Zinc Finger Protein 1) and gfl-1 (GAS41- like), as well as genes with chromatin function, mes-3, mes-4, mes- 6 , and found that at some dsRNA concentrations this led to a decrease in RNAi efficiency when additional genes were targeted. We found using an RNAi screen to investigate RNAi-TGS, that targeting $z f p-1$ and $g f l-1$ reduced the efficiency of RNAi-TGS (Table 3). These genes are probably not important for RNAi-PTGS. For example, a $z f p-1$ deletion mutant $z f p-1$ (ok554) was completely sensitive to RNAi when we used bacteria expressing dsRNA specific to either pos-1, unc-22, or alg-1/2 genes. It is possible that under conditions used by Dudley et al. (2002) for dsRNA injec- tions, the RNAi pathway initiates transcriptional silencing.

We find it very intriguing that Polycomb Group gene sop-2 is important for the RNAi-TGS pathway. Sop-2 has been recently shown to bind single stranded and double stranded RNA, and RNA binding by this protein is important for its function in Hox gene repression (Zhang et al. 2004a,b).

The requirement for the alg-1 gene in RNAi-TGS clearly separates this process from RNAi-PTGS where alg-1 is not essential (Grishok et al. 2001). Alg-1 and Alg-2 are PAZ-PIWI proteins that play a critical role in the production and function of miRNAs in C. elegans (Grishok et al. 2001). miRNAs primarily negatively regulate their targets at the level of translation, but can also target mRNA cleavage (for review, see Bartel 2004). It is not clear whether Alg-1 plays a role in transcriptional silencing directly, similarly to the $S$. pombe protein Agol (Noma et al. 2004; Verdel et al. 2004), or whether some miRNAs regulated by Alg-1 have targets involved in RNAi-TGS.

RNAi-TGS might have a role in transposon silencing in C. elegans. We found that 11 genes, identified in a screen for transposon silencing factors in the germline by Vastenhouw and colleagues, also affected RNAi-TGS of the elt-2::gfp/LacZ (Table 3). Transposon silencing in C. elegans is thought to occur mostly post-transcriptionally, based on the lack of significant reduction of the pre-mRNA (Sijen and Plasterk 2003). However, some genes with potential function in the nucleus, such as the D2096.8 gene (encoding a potential nucleosome assembly protein) and npp-4 (encoding nucleoporin), affect both transposon silencing (Vastenhouw et al. 2003) and the RNAi-TGS described here (Table 3 ).

A dsRNA feeding library containing bacteria targeting almost all C. elegans genes is a useful tool for large-scale phenotypic screens (Kamath et al. 2003). However, the finding that the vector used for construction of the library could elicit homology-dependent silencing of certain transgenes should be taken into account when transgenic worm strains are used for large-scale screens.

\section{Materials and methods}

\section{C. elegans strains}

Worms were maintained on NGM plates seeded with OP50 bacteria. The following strains were used: LGI, rrf-1(pk1417); LGII, rrf-3 (pk1426); LGIII, hpl-2 (ok1061), rde-4 (ne299), zfp-1 (ok554); LGV, rde-1 (ne300); LGX, alg-1 (gk214), elt-2::gfp/ LacZ. Additional transgenic strains used are listed in Table 1.

\section{elt- $2::$ gfp/LacZ silencing by feeding worms dsRNA}

RNAi by feeding was performed essentially as described in Conte and Mello (2003). Briefly, HT115 (DE3) bacteria were transformed with L4440 feeding vector and cultured on LB plates with $50 \mu \mathrm{g} / \mathrm{mL}$ ampicillin and $15 \mu \mathrm{g} / \mathrm{mL}$ tetracycline. A single colony was inoculated into $10-20 \mathrm{~mL}$ bacterial cultures in LB/Amp overnight; these cultures were used for seeding NGM/Amp/IPTG plates. HDAC inhibitors were added to the 
bacterial cultures to the final concentrations indicated in Table 2 before seeding the plates. Single adult elt-2::gfp/LacZ or rrf3;elt-2::gfp/LacZ hermaphrodites were put on each plate and their L4 or adult progeny were scored for GFP expression in the intestine. Experiments were performed in triplicate for each bacterial strain tested for silencing. Worms grown on plates were directly viewed with Zeiss Axoplan 2 microscope at 100x magnification using the appropriate filter. OpenLab 3.1.7 software (Improvision) was used for capturing images $(100 \times)$ of live worms put on $2 \%$ agarose pads; the same exposure time (typically $\sim 500 \mathrm{msec}$ ) was used for capturing images to be compared in the same experiment.

\section{L4440 clones}

The L4440 cloning vector, as well as mes-1, let-2, pos-1, and unc-22 clones were obtained from the Mello lab. Fragments of $d c r-1, h p l-2$, and $a l g-1$ genes were amplified by PCR from $C$. elegans genomic DNA and cloned into L4440. The following primers were used: $d c r-1$ (forward, GGTAAGAGCTGATTTA CAATG; reverse, GAATCTTTAATCGGTCTACGA); hpl-2 (forward, ATGTCGAGCAAATCAACAAAGC; reverse, TTA AAGCTCGTCGGCTTTTGGGT); alg-1 (forward, ATGTCCG GCGGGCCGCAATATTTGCC; reverse, TCAAATAGAAAC TAAATTAAATGCC). Additional bacterial clones containing L4440 with inserts of C. elegans genes constructed by Ahringer's group were obtained from MRC Geneservice.

\section{Soaking C. elegans in dsRNA solution}

LacZ dsRNA (1 kb) was prepared by in vitro transcription with $\mathrm{T} 7$ polymerase using PCR product as a template (Ambion). A portion of a LacZ gene (1 kb) was amplified by PCR from genomic DNA of elt-2::gfp/LacZ strain. PCR product was flanked with T7 promoter sequences (GCGTAATACGACTCAC TATA) on both $5^{\prime}$ ends. Primers used for PCR amplification of LacZ sequence are as follows: forward, ATGACCATGATTAC GGATTC; reverse, CAGCAGACCATTTTCAATC. A total of 10-15 adult elt-2::gfp/LacZ worms were soaked in $20 \mu \mathrm{L}$ of 1 $\mathrm{mg} / \mathrm{mL}$ LacZ dsRNA or water for $24 \mathrm{~h}$, and their adult progeny was examined for GFP expression. Typically, progeny of LacZ dsRNA-soaked worms developed complete silencing of GFP in the intestine. Total RNA was prepared from the silenced progeny of soaked worms.

\section{$R T-P C R$}

Tri Reagent (MRC) was used for total RNA preparation from $C$. elegans, RNA was DNase treated with DNA-free reagent (Ambion). Of the total C. elegans RNA, $0.25 \mu \mathrm{g}$ was used in $20 \mu \mathrm{L}$ $\mathrm{RT}$ reaction with random hexamer primers (Ambion), and $1 \mu \mathrm{L}$ of RT reaction was used to template a $50-\mu \mathrm{L}$ PCR reaction. Primers used for amplification of 2-kb plasmid sequence are as follows: forward, AGGTGGCACTTTTCGGGGA; reverse, GCTTCCTCGCTCACTGACTCGC. Primers specific for elt2::gfp/LacZ exon sequences are as follows: forward, exon 14, CTGCCATTGTCAGACATGT; reverse, exon 16, CAGAG GCACGGGCGCGAGATG. Primers specific for elt-2::gfp/ LacZ intron sequences are as follows: forward, intron 14, CTAACTAACATGTTTCATTTAAATTTTCAG; reverse, intron 15 , TAGTTAGTAGAACTCAGTTTAAACTTAC. Primers specific for ama-1 exon sequences are as follows: forward, exon 3, GATCTACGATCTGTGCAAAGC; reverse, exon 4, CGAGTACTCGTTCGGCGGT.

\section{Quantitative real-time PCR}

The TaqMan system (Applied Biosystems) was used for cDNA amplification and SYBR Green dye (Qiagen) for the amplifica- tion of DNA in ChIP assays. Reactions were run in triplicate on an ABI Prism 7000 Real-time PCR machine (Applied Biosystems). Relative fold changes were calculated using the $2^{-\Delta \Delta C t}$ method. TaqMan probe and primers sets were designed using Primer Express Software (Applied Biosystems), probes for mature mRNAs were designed to span exon-exon junction, and the probe for $g f p / L a c Z$ pre-mRNA was intron specific. The sequences used were as follows: for $g f p / L a c Z$ mRNA, forward, exon 8, CAGGTCATGGATGAGCAGACG; reverse, exon 9, ACGGCGTTAAAGTTGTTCTGCTT; probe, TGCAGGAT ATCCTGCTGAT; for $g f p / L a c Z$ pre-mRNA, forward, exon 8 , CAGGTCATGGATGAGCAGACG; reverse, intron 8, AA AATTTAAA TGTTTAAA GTTAG TTAGTAACGAATAGTTT; probe, TGGTGCAGGATGTAAGTT; for ama-1 mRNA, forward, GATGATCCGATGAATGATGGAAAG; reverse, CGG TATGATGGTTGATAGCGACC; probe, AGGTCGCAGGTG GATG; for act-3, forward, GCAGAAGGAAATCACCGC TCTTG; reverse, GCGATGATCTTGATCTTCATGG; for $g f p /$ LacZ DNA amplification, primers were the same as for premRNA.

\section{ChIP}

For preparation of protein lysates $\sim 300-500 \mu \mathrm{L}$ of packed $\mathrm{L} 4$ or young adult animals were used for each immunoprecipitation. Formaldehyde fixing, lysate preparation, and sonication was done according to Chu et al. (2002). ChIP was performed with Anti-acetyl-Histone H4 antiserum (\#06-866 Upstate Biotechnology) according to the manufacturer's protocol; the same conditions were used for ChIP with 8WG16 Polymerase II antibodies (Covance).

\section{Acknowledgments}

We thank D. Conte Jr., C. Mello, S. van den Heuvel, M. Krause, and V. Ambros for providing strains and reagents. hpl-2 and alg-1 deletion mutants were provided by the C. elegans Gene Knockout Project at OMRF and C. elegans Reverse Genetics Core Facility at UBC, which are part of the International $C$. elegans Gene Knockout Consortium. Some strains used in this study were obtained from the Caenorhabditis Genetics Center, which is funded by the NIH National Center for Research Resources (NCRR). C. elegans RNAi feeding library, purchased from MRC Geneservice, was constructed by J. Ahringer's group at the The Wellcome CRC Institute. We thank R. Chan for advice on ChIP; L. Aleman for advice on real-time PCR; J. Neilson, A. Seila, and J. Doench for critical reading of the manuscript; and members of the Sharp Lab for discussions. This work was supported by United States Public Health Service MERIT Award R37-GM34277 from the National Institutes of Health and PO1-CA42063 from the National Cancer Institute to P.A.S., The Damon Runyon Cancer Research Foundation Fellowship DRG 1724-02 to A.G., and partially by a Cancer Center Support (core) grant P30-CA 14051 from the National Cancer Institute.

\section{References}

Bartel, D.P. 2004. MicroRNAs: Genomics, biogenesis, mechanism, and function. Cell 116: 281-297.

Bernstein, E., Caudy, A.A., Hammond, S.M., and Hannon, G.J. 2001. Role for a bidentate ribonuclease in the initiation step of RNA interference. Nature 409: 363-366.

Caudy, A.A., Ketting, R.F., Hammond, S.M., Denli, A.M., Bathoorn, A.M., Tops, B.B., Silva, J.M., Myers, M.M., Hannon, G.J., and Plasterk, R.H. 2003. A micrococcal nuclease homologue in RNAi effector complexes. Nature 425: 411414 . 
Chan, S.W., Zilberman, D., Xie, Z., Johansen, L.K., Carrington, J.C., and Jacobsen, S.E. 2004. RNA silencing genes control de novo DNA methylation. Science 303: 1336.

Chu, D.S., Dawes, H.E., Lieb, J.D., Chan, R.C., Kuo, A.F., and Meyer, B.J. 2002. A molecular link between gene-specific and chromosome-wide transcriptional repression. Genes \& Dev. 16: 796-805.

Conte Jr., D. and Mello, C.C. 2003. RNA Interference in Caenorhabditis Elegans. In Current protocols in molecular biology (eds. F.M. Ausubel et al.), 26.3. John Wiley and Sons Inc., Hoboken, NJ.

Couteau, F., Guerry, F., Muller, F., and Palladino, F. 2002. A heterochromatin protein 1 homologue in Caenorhabditis elegans acts in germline and vulval development. EMBO Rep. 3: $235-241$.

Dernburg, A.F., Zalevsky, J., Colaiacovo, M.P., and Villeneuve, A.M. 2000. Transgene-mediated cosuppression in the C. elegans germ line. Genes \& Dev. 14: 1578-1583.

Domeier, M.E., Morse, D.P., Knight, S.W., Portereiko, M., Bass, B.L., and Mango, S.E. 2000. A link between RNA interference and nonsense-mediated decay in Caenorhabditis elegans. Science 289: 1928-1931.

Dudley, N.R., Labbe, J.C., and Goldstein, B. 2002. Using RNA interference to identify genes required for RNA interference. Proc. Natl. Acad. Sci. 99: 4191-4196.

Elbashir, S.M., Lendeckel, W., and Tuschl, T. 2001. RNA interference is mediated by 21- and 22-nucleotide RNAs. Genes \& Dev. 15: 188-200.

Fire, A., Xu, S., Montgomery, M.K., Kostas, S.A., Driver, S.E., and Mello, C.C. 1998. Potent and specific genetic interference by double-stranded RNA in Caenorhabditis elegans. Nature 391: 806-811.

Fujita, M., Takasaki, T., Nakajima, N., Kawano, T., Shimura, Y., and Sakamoto, H. 2002. MRG-1, a mortality factor-related chromodomain protein, is required maternally for primordial germ cells to initiate mitotic proliferation in C. elegans. Mech. Dev. 114: 61-69.

Fukushige, T., Hawkins, M.G., and McGhee, J.D. 1998. The GATA-factor elt-2 is essential for formation of the Caenorhabditis elegans intestine. Dev. Biol. 198: 286-302.

Grishok, A., Pasquinelli, A.E., Conte, D., Li, N., Parrish, S., Ha, I., Baillie, D.L., Fire, A., Ruvkun, G., and Mello, C.C. 2001. Genes and mechanisms related to RNA interference regulate expression of the small temporal RNAs that control C. elegans developmental timing. Cell 106: 23-34.

Hall, I.M., Shankaranarayana, G.D., Noma, K., Ayoub, N., Cohen, A., and Grewal, S.I. 2002. Establishment and maintenance of a heterochromatin domain. Science 297: 2232-2237.

Hamilton, A.J. and Baulcombe, D.C. 1999. A species of small antisense RNA in posttranscriptional gene silencing in plants. Science 286: 950-952.

Hammond, S.M., Bernstein, E., Beach, D., and Hannon, G.J. 2000. An RNA-directed nuclease mediates post-transcriptional gene silencing in Drosophila cells. Nature 404: 293296.

Kamath, R.S. and Ahringer, J. 2003. Genome-wide RNAi screening in Caenorhabditis elegans. Methods 30: 313-321.

Kelly, W.G. and Fire, A. 1998. Chromatin silencing and the maintenance of a functional germline in Caenorhabditis elegans. Development 125: 2451-2456.

Kelly, W.G., Xu, S., Montgomery, M.K., and Fire, A. 1997. Distinct requirements for somatic and germline expression of a generally expressed Caernorhabditis elegans gene. Genetics 146: $227-238$.

Kelly, W.G., Schaner, C.E., Dernburg, A.F., Lee, M.H., Kim,
S.K., Villeneuve, A.M., and Reinke, V. 2002. X-chromosome silencing in the germline of $C$. elegans. Development 129: 479-492.

Ketting, R.F. and Plasterk, R.H. 2000. A genetic link between co-suppression and RNA interference in C. elegans. Nature 404: 296-298.

Ketting, R.F., Haverkamp, T.H., van Luenen, H.G., and Plasterk, R.H. 1999. Mut-7 of C. elegans, required for transposon silencing and RNA interference, is a homolog of Werner syndrome helicase and RNaseD. Cell 99: 133-141.

Knight, S.W. and Bass, B.L. 2001. A role for the RNase III enzyme DCR-1 in RNA interference and germ line development in Caenorhabditis elegans. Science 293: 2269-2271.

. 2002. The role of RNA editing by ADARs in RNAi. Mol. Cell 10: 809-817.

Mello, C.C., Kramer, J.M., Stinchcomb, D., and Ambros, V. 1991. Efficient gene transfer in C.elegans: Extrachromosomal maintenance and integration of transforming sequences. $E M B O$ I. 10: 3959-3970.

Mette, M.F., Aufsatz, W., van der Winden, J., Matzke, M.A., and Matzke, A.J. 2000. Transcriptional silencing and promoter methylation triggered by double-stranded RNA. EMBO $J$. 19: 5194-5201.

Montgomery, M.K., Xu, S., and Fire, A. 1998. RNA as a target of double-stranded RNA-mediated genetic interference in Caenorhabditis elegans. Proc. Natl. Acad. Sci. 95: 15502-15507.

Ngo, H., Tschudi, C., Gull, K., and Ullu, E. 1998. Doublestranded RNA induces mRNA degradation in Trypanosoma brucei. Proc. Natl. Acad. Sci. 95: 14687-14692.

Noma, K.I., Sugiyama, T., Cam. H., Verdel, A., Zofall, M., Jia, S., Moazed, D., and Grewal, S.I. 2004. RITS acts in cis to promote RNA interference-mediated transcriptional and posttranscriptional silencing. Nat. Genet. 36: 1174-1180.

Pal-Bhadra, M., Bhadra, U., and Birchler, J.A. 2002. RNAi related mechanisms affect both transcriptional and posttranscriptional transgene silencing in Drosophila. Mol. Cell 9: 315327.

Pal-Bhadra, M., Leibovitch, B.A., Gandhi, S.G., Rao, M., Bhadra, U., Birchler, J.A., and Elgin, S.C. 2004. Heterochromatic silencing and HP1 localization in Drosophila are dependent on the RNAi machinery. Science 303: 669-672.

Pothof, J., van Haaften, G., Thijssen, K., Kamath, R.S., Fraser, A.G., Ahringer, J., Plasterk, R.H., and Tijsterman, M. 2003. Identification of genes that protect the C. elegans genome against mutations by genome-wide RNAi. Genes \& Dev. 17: 443-448.

Reinhart, B.J. and Bartel, D.P. 2002. Small RNAs correspond to centromere heterochromatic repeats. Science 297: 1831.

Sijen, T. and Plasterk, R.H. 2003. Transposon silencing in the Caenorhabditis elegans germ line by natural RNAi. Nature 426: 310-314.

Sijen, T., Fleenor, J., Simmer, F., Thijssen, K.L., Parrish, S., Timmons, L., Plasterk, R.H., and Fire, A. 2001. On the role of RNA amplification in dsRNA-triggered gene silencing. Cell 107: 465-476.

Simmer, F., Tijsterman, M., Parrish, S., Koushika, S.P., Nonet, M.L., Fire, A., Ahringer, J., and Plasterk, R.H. 2002. Loss of the putative RNA-directed RNA polymerase RRF-3 makes C. elegans hypersensitive to RNAi. Curr. Biol. 12: $1317-1319$.

Smardon, A., Spoerke, J.M., Stacey, S.C., Klein, M.E., Mackin, N., and Maine, E.M. 2000. EGO-1 is related to RNA-directed RNA polymerase and functions in germ-line development and RNA interference in C. elegans. Curr. Biol. 10: 169-178.

Solari, F., Bateman, A., and Ahringer, J. 1999. The Caenorhabditis elegans genes egl-27 and egr-1 are similar to MTA1, a 


\section{Grishok et al.}

member of a chromatin regulatory complex, and are redundantly required for embryonic patterning. Development 126: 2483-2494.

Strome, S., Powers, J., Dunn, M., Reese, K., Malone, C.J., White, J., Seydoux, G., and Saxton, W. 2001. Spindle dynamics and the role of $\gamma$-tubulin in early Caenorhabditis elegans embryos. Mol. Biol. Cell 12: 1751-1764.

Tabara, H., Grishok, A., and Mello, C.C. 1998. RNAi in C. elegans: Soaking in the genome sequence. Science 282: 430431.

Tabara, H., Sarkissian, M., Kelly, W.G., Fleenor, J., Grishok, A., Timmons, L., Fire, A., and Mello, C.C. 1999. The rde-1 gene, RNA interference, and transposon silencing in C. elegans. Cell 99: 123-132.

Tabara, H., Yigit, E., Siomi, H., and Mello, C.C. 2002. The dsRNA binding protein RDE-4 interacts with RDE-1, DCR-1, and a DExH-box helicase to direct RNAi in C. elegans. Cell 109: 861-871.

Takanami, T., Sato, S., Ishihara, T., Katsura, I., Takahashi, H., and Higashitani, A. 1998. Characterization of a Caenorhabditis elegans recA-like gene Ce-rdh-1 involved in meiotic recombination. DNA Res. 5: 373-377.

Terranova, R., Pujol, N., Fasano, L., and Djabali, M. 2002. Characterisation of set-1, a conserved PR/SET domain gene in Caenorhabditis elegans. Gene 292: 33-41.

Tijsterman, M., May, R.C., Simmer, F., Okihara, K.L., and Plasterk, R.H. 2004. Genes required for systemic RNA interference in Caenorhabditis elegans. Curr. Biol. 14: 111-116.

Timmons, L. and Fire, A. 1998. Specific interference by ingested dsRNA. Nature 395: 854.

Tuschl, T., Zamore, P.D., Lehmann, R., Bartel, D.P., and Sharp, P.A. 1999. Targeted mRNA degradation by double-stranded RNA in vitro. Genes \& Dev. 13: 3191-3197.

Vastenhouw, N.L., Fischer, S.E., Robert, V.J., Thijssen, K.L., Fraser, A.G., Kamath, R.S., Ahringer, J., and Plasterk, R.H. 2003. A genome-wide screen identifies 27 genes involved in transposon silencing in C. elegans. Curr. Biol. 13: 1311-1316.

Verdel, A., Jia, S., Gerber, S., Sugiyama, T., Gygi, S., Grewal, S.I., and Moazed, D. 2004. RNAi-mediated targeting of heterochromatin by the RITS complex. Science 303: 672-676.

Volpe, T.A., Kidner, C., Hall, I.M., Teng, G., Grewal, S.I., and Martienssen, R.A. 2002. Regulation of heterochromatic silencing and histone H3 lysine-9 methylation by RNAi. Science 297: 1833-1837.

Wassenegger, M., Heimes, S., Riedel, L., and Sanger, H.L. 1994. RNA-directed de novo methylation of genomic sequences in plants. Cell 76: 567-576.

Wickens, M., Bernstein, D.S., Kimble, J., and Parker, R. 2002. A PUF family portrait: 3'UTR regulation as a way of life. Trends Genet. 18: 150-157.

Xie, Z., Johansen, L.K., Gustafson, A.M., Kasschau, K.D., Lellis, A.D., Zilberman, D., Jacobsen, S.E., and Carrington, J.C. 2004. Genetic and functional diversification of small RNA pathways in plants. PLoS Biol. 2: E104.

Zamore, P.D., Tuschl, T., Sharp, P.A., and Bartel, D.P. 2000. RNAi: Double-stranded RNA directs the ATP-dependent cleavage of mRNA at 21 to 23 nucleotide intervals. Cell 101: 25-33.

Zhang, H., Christoforou, A., Aravind, L., Emmons, S.W., van den Heuvel, S., and Haber, D.A. 2004a. The C. elegans Polycomb gene sop-2 encodes an RNA binding protein. Mol. Cell 14: $841-847$.

Zhang, H., Smolen, G.A., Palmer, R., Christoforou, A., van den Heuvel, S., and Haber, D.A. 2004b. SUMO modification is required for in vivo Hox gene regulation by the Caenorhabditis elegans Polycomb group protein SOP-2. Nat. Genet.
36: $507-511$.

Zilberman, D., Cao, X., and Jacobsen, S.E. 2003. ARGONAUTE4 control of locus-specific siRNA accumulation and DNA and histone methylation. Science 299: 716-719. 


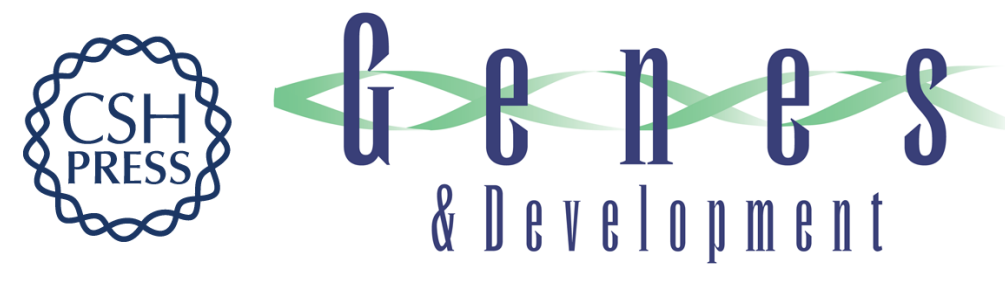

\section{Transcriptional silencing of a transgene by RNAi in the soma of $C$. elegans}

Alla Grishok, Jina L. Sinskey and Phillip A. Sharp

Genes Dev. 2005, 19:

Access the most recent version at doi:10.1101/gad.1247705

Supplemental http://genesdev.cshlp.org/content/suppl/2005/03/02/gad.1247705.DC1
Material

References This article cites 57 articles, 24 of which can be accessed free at: http://genesdev.cshlp.org/content/19/6/683.full.html\#ref-list-1

License

Email Alerting Receive free email alerts when new articles cite this article - sign up in the box at the top Service right corner of the article or click here.

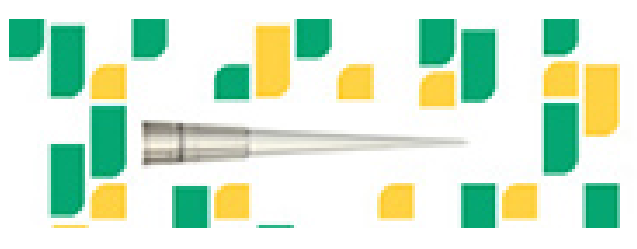

Focused on your science. 